\title{
Model for vocabulary selection of sensitive topics: An example from pain-related
}

\section{vocabulary}

\author{
*Ensa Johnson, PhD, MA(AAC), BA Hons (AAC), B Prim Ed \\ Lecturer
}

Centre for Augmentative and Alternative Communication

University of Pretoria

Pretoria, South Africa

Juan Bornman, PhD, M(Comm Path), B(Log)

Professor and Director

Centre for Augmentative and Alternative Communication

University of Pretoria

Pretoria, South Africa

Kerstin Tönsing, PhD, MA(AAC), B(Log)

Senior Lecturer

Centre for Augmentative and Alternative Communication

University of Pretoria

Pretoria, South Africa

\footnotetext{
*Correspondence:

Ensa Johnson, PhD

Centre for Augmentative and Alternative Communication, Communication and Pathology Building,

University of Pretoria, Corner of Lynnwood Road and Roper Street, Hatfield, 0083

e-mail: ensa.johnson@up.ac.za

Phone: +27 124202001

Fax: +27865100841
} 


\begin{abstract}
Vocabulary selection for graphic symbol-based AAC systems is important to enable persons with significant communication difficulties to express a variety of communication functions to indicate needs and wants, develop social closeness and to fulfill social etiquette. For persons who experience pain, abuse, bullying or neglect, it is essential to be able to communicate about sensitive issues. However, published core vocabulary lists allow limited scope for communicating about sensitive topics, due mainly to the techniques employed to determine such lists (e.g., observations or recording of communication patterns of peers with typical development during fun-based or daily activities). This article is based on the outcome of a study of children's pain-related vocabulary. Based on the study, we propose a model for selecting vocabulary on sensitive topics. The model consists of four phases: (i) Using hypothetical scenarios; (ii) Considering different perspectives that may affect vocabulary selection; (iii) Involving direct stakeholders, and (iv) Customizing vocabulary.
\end{abstract}

\title{
KEYWORDS
}

Augmentative and alternative communication, sensitive topics, stakeholder review, vocabulary, vocabulary selection

\section{LEARNING OBJECTIVES}

After reading this article, the learner should be able to

(i) explain why vocabulary for sensitive topics should be identified for persons with significant communication difficulties;

(ii) discuss the various phases that could be employed when selecting vocabulary for sensitive topics; 
(iii) explain how the opinions of stakeholders could contribute to the best suitable vocabulary selected for a specific individual.

\section{CEU QUESTIONS AND ANSWERS (correct answers are bolded)}

1. Which of the following is NOT an appropriate method for vocabulary selection in AAC?
A. Environmental inventories
B. Categorical inventories
C. Published source lists
D. Core vocabulary lists
E. Self-generation

2. How is core vocabulary lists typically compiled?
A. Inventories
B. Interviewing parents activity

\section{Recording conversation of peers during an activity \\ E. Blank page approach}

C. Observing peers and person with complex communication disabilities in an

3. What are the factors that complicate vocabulary selection for sensitive topics?
A. Words related to such topics typically do not appear on core word lists.
B. Obtaining communication samples from peers during the discussion of sensitive topics is difficult.
C. Persons using AAC typically do not discuss sensitive topics.
D. A and B.
E. None of the above. 
4. Which is NOT a factor that should be considered as it could potentially influence the specific informants' vocabulary suggestions?
A. Gender
B. Age
C. Language background
D. Experience
E. Profession

5. Which of the following is NOT included as one of the four phases of Johnson's (2015) model for vocabulary selection of sensitive topics?
A. Customizing vocabulary
B. Involving direct stakeholders
C. Observations
D. Using hypothetical scenarios
E. Considering different perspectives that may influence vocabulary selection

\section{DISCLOSURES}

Ensa Johnson receives a salary from the University of Pretoria. The financial assistance of the National Research Foundation (NRF) 10.13039/501100001321 [86447] and the Margaret McNamara Memorial Fund (MMMF) towards this research project is hereby acknowledged. Opinions expressed are attributable to the authors and do not necessarily reflect the official viewpoint of either the MMMF or the NRF.

Juan Bornman receives a salary from the University of Pretoria and royalties from Van Schaik Publishers for her textbook.

Kerstin Tonsing receives a salary from the University of Pretoria.

There are no relevant nonfinancial relationships for any of the authors. 
Despite recent advances in the field of AAC, vocabulary needs of nonliterate (preliterate and illiterate) children and adults with significant communication difficulties continue to be of concern in the AAC community ${ }^{1}$. Persons with typical development spontaneously use spoken language the moment the need arises to achieve various communication goals, such as providing information, indicating needs and wants, developing social closeness and fulfilling the demands of social etiquette ${ }^{2,3}$. In contrast, persons in need of augmentative and alternative communication (AAC) who make use of single-meaning graphic symbol-based AAC systems are unable to spontaneously express an unlimited number of messages and words. They need to rely on pre-selected messages (typically chosen by others) stored on their AAC systems to communicate and achieve their communication goals ${ }^{4}$. Therefore, Snodgrass, Stoner and Angell ${ }^{5}$ advise that the vocabulary selection process should be conducted with care, since it directly influences the communication achievements and successes of the person using single-meaning graphic symbol-based AAC.

It is typically the role of speech-language pathologists (SLPs), together with parents or caregivers and other role players, to select suitable vocabulary and to continue updating this vocabulary to assist the person in need of AAC to achieve specific communication goals, for example, to communicate pain ${ }^{5,6}$. However, previous studies have shown that vocabulary selection by proxy often results in inappropriate or insufficient vocabulary that does not meet the needs of the person using AAC and does not reflect his or her specific individual characteristics, personality, context or developmental stage ${ }^{7}$. The process of predicting what vocabulary will be needed has been described as a challenging one, as it is not something natural speakers routinely do. It may be even more challenging to attempt to predict the words and messages needed by someone $\mathrm{else}^{7,8}$.

Vocabulary selection is important for the development of age-appropriate and culturally relevant communication boards and speech-generating devices ${ }^{9}$. Vocabulary 
selection describes the process of choosing a set of words from more than hundreds of options ${ }^{10}$. Vocabulary should be selected to (i) support persons with severe communication difficulties to attain various communication goals (not merely to satisfy their needs and wants); (ii) address diverse communication needs of each individual, and (iii) nurture the development of children's language skills ${ }^{11,12}$. Vocabulary selection is a complicated, timeconsuming, cumbersome, but essential procedure to ensure that persons with severe communication difficulties have access to relevant vocabulary to express their individual circumstances $^{5,13}$. A substantial amount of AAC research is available related to various aspects of vocabulary selection for persons with significant communication difficulties ${ }^{4,7,14-19}$.

\section{Vocabulary Selection Techniques}

Various vocabulary selection techniques have been implemented in an attempt to ensure relevant and appropriate vocabulary for persons who use or require AAC. Seven of these techniques and how they are applied are briefly discussed next:

(i) Environmental Inventory - observing the individual with severe communication difficulties and peers with typical development performing an activity in natural contexts and noting which vocabulary is used by the peers with typical development and which words are needed by the child with complex communication difficulties in order to allow participation in the specific activity ${ }^{7,20}$. This technique typically results in activitybased vocabulary ${ }^{21,22}$.

(ii) Categorical Inventory - obtaining input from informants such as the individual him-/herself, as well as from familiar communication partners to suggest words applicable in various word categories, such as people, places, feelings $s^{4,12,23}$. This technique is successful for fringe vocabulary that will be very individual specific. 
(iii) Core Vocabulary Lists - using core vocabulary lists generated from research to explore the frequency of words used by similar-aged individuals with typical development ${ }^{14,16,24}$. This is particularly helpful for children who require a vocabulary that will continue to grow with them as they develop.

(iv) Published Source Lists - using lists such as developmental language inventories and curriculum guides ${ }^{16}$. This technique enables children with complex communication difficulties to participate in classroom activities as it gives them access to the vocabulary related to learning.

(v) Communication Diary - using vocabulary items gathered by writing down or capturing everything the person who uses AAC attempts to communicate (e.g., saving messages or logging communication breakdowns). The diary provides fringe vocabulary and is effective if the person in need of AAC has a strong routinized diary with a high predictability of activities $^{25,26}$.

(vi) Blank Page - writing down all possible words that the informants, in their opinion, perceive to be useful for the person who uses $\mathrm{AAC}^{27}$. This technique is effective for first vocabulary selection as it allows the list to start with meaningful content for the specific individual.

(vii) Topic-based vocabulary - typical conversational topics have been determined in various studies ${ }^{13,20,28}$ and can be used as a basis for predicting appropriate vocabulary for different topics.

In addition to the above vocabulary selection techniques, Balandin and Iacono ${ }^{8,13}$ and Schlosser ${ }^{29}$ emphasized the importance of using stakeholder reviews to socially validate the selected vocabulary. Social validation of vocabulary is a method by means of which to 
improve the efficiency and acceptability of AAC and guarantee stakeholder accountability ${ }^{1}$. It would seem most logical and important for the person using AAC him-/herself to provide input on the selected vocabulary. However, for some persons who use AAC, particularly those who have limited language and literacy skills, the opinions of others who also rely on AAC may be elicited. As Bornman and Bryen ${ }^{1, p .175}$ state: "Using adults who use AAC as key stakeholders to verify vocabulary for illiterate peers, particularly when sensitive topics are at hand, may be an appropriate avenue for social validation."

Determining vocabulary for sensitive topics such as pain or abuse may pose a challenge in augmentative and alternative communication (AAC) service delivery. Core vocabulary lists that have been compiled by determining the most frequently used words from recordings of peers with typical development across different activities typically do not contain situation-specific nouns and verbs. Rather, they contain words that are typically used across different situations. Such words tend to have conceptual rather than concrete referents, and many may be closed class-function words needed to build grammatical sentences ${ }^{5,15}$. Specific words related to sensitive topics such as abuse or pain are unlikely to appear as core words for two possible reasons - first, they may be situation-specific words that are not used with high enough frequencies to be counted as core vocabulary, and, second, the situations during which peers were recorded to determine core words are in all likelihood not situations during which the peers were actually exposed to any trauma, such as abuse or pain. While core words are of utmost importance in building a more generative system that allows multiword constructions beyond single-word utterances, core vocabulary should always be supplemented by fringe vocabulary - situation and person-specific additional words that allow for a full range of specific messages to be expressed ${ }^{30}$.

Fringe vocabulary may be selected using one of the other methods mentioned above. However, vocabulary related to sensitive topics are still be unlikely to be selected as fringe 
vocabulary using these methods. Activity-based approaches, for example, have led to published resources that focus primarily on fun activities (e.g., book reading or play) or activities of daily living (e.g., eating, dressing) due to their motivational value ${ }^{14,18,21,31}$. More unpleasant and sensitive topics, such as pain or abuse were often not considered. Similarly, categorical inventories may also not lead to the identification of vocabulary related to sensitive topics or unpleasant experiences. The tendency by caregivers and service providers to avoid the discussion of such difficult topics may also be partly to blame $\mathrm{e}^{9,32}$. As a result, graphic symbol-based AAC systems for children often lack words related to sensitive topics (e.g., pain, abuse, death, bullying or neglect), and therefore children may be unable to formulate the necessary messages when they try to inform their communication partners of these sensitive issues. Alternative methods should thus be investigated to arrive at a relevant list of pain-related vocabulary.

Observations and the recording of actual spoken communication during specific events have also been used as methods to determine vocabulary ${ }^{14}$. Such methodologies have likewise been used in studies that focused on children's pain vocabulary, for instance observation of pediatric patients after surgery ${ }^{33}$ and making video recordings of children receiving injections ${ }^{34}$. Regrettably, video- or audio-recording children's interactions during their pain experiences could add stress to already stressful and sensitive situations. Moreover, such methods could be seen as violating the ethical principles of non-maleficence (the obligation to do no harm) and respect for human dignity and privacy ${ }^{35}$. This led to the question: What are the appropriate methods that could be used to determine vocabulary for sensitive topics, such as pain, abuse, bullying and neglect?

Consequently, the main aim of this article is to propose a model for the selection of vocabulary to allow children with significant communication difficulties to communicate about sensitive topics such as pain, abuse (i.e., sexual, physical, verbal abuse), bullying, death 
or neglect. The article is based on the outcome of a doctoral study that identified children's pain-related vocabulary and subsequently proposed the Johnson ${ }^{36}$ model for the selection of vocabulary to discuss sensitive topics ${ }^{36}$.

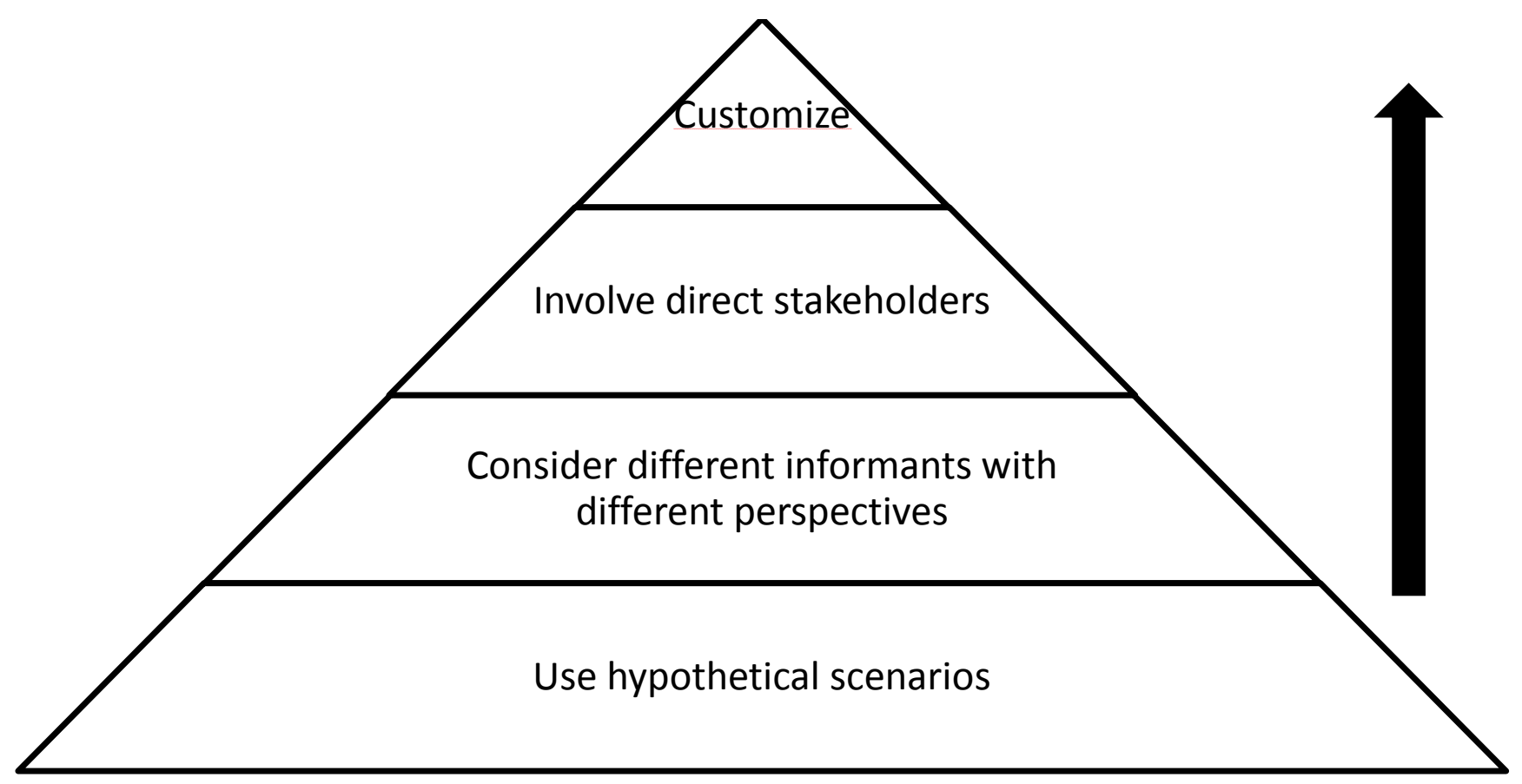

Figure 1. Model for the selection of vocabulary for sensitive topics ${ }^{36}$

Johnson's model ${ }^{23,36}$ (see Figure 1) proposes four distinct phases, namely: (i) using hypothetical scenarios; (ii) considering different perspectives and factors that may affect vocabulary selection; (iii) involving direct stakeholders (social validation) and (iv) customizing vocabulary for each individual. Each of these phases will be addressed in more detail below.

\section{PHASE 1: HYPOTHETICAL SCENARIOS}

Johnson's model first suggests that hypothetical scenarios with semi-structured follow-up questions should be developed for use during interviews, in focus group 
discussions, or by means of questionnaires ${ }^{23,36}$. Using hypothetical scenarios to elicit vocabulary from peers with typical development is less threatening than being asked directly about real-life experiences ${ }^{37}$ and both children and adults can easily relate to such scenarios ${ }^{38}$. The use of custom-designed hypothetical scenarios (applicable to a specific topic) can help participants to freely share information about sensitive topics and experience it as less stressful and less invasive than when they are asked to talk about their own lived experiences $^{39,40}$.

Written vignettes or short stories that simulate real experiences ${ }^{41}$ have, for example, been used to conduct research among adults into sensitive topics such as drug-related issues ${ }^{40}$, abuse of the elderly ${ }^{42}$, and HIV/Aids ${ }^{43}$. The use of vignettes helped children and adults to distance themselves from a sensitive topic and allowed them to share their ideas without feeling personally embarrassed or exposed during the interview ${ }^{41}$. Questions may, for example, be asked on how they think the character in the short stories should ideally act or how they think the character should respond or react in the specific circumstance. This method of discussing painful scenarios does not result in increased secondary stress experienced by the individual, as would have been the case if he/she had been observed or asked to relive a sensitive event ${ }^{39,40}$. The use of specific scenarios can furthermore assist in eliciting more authentic vocabulary than may be possible through topic or activity-based approaches $^{8}$.

Depending on the individual's age, hypothetical scenarios in the form of vignettes can be presented either in the form of text (i.e., a written story), as a verbally narrated story told with the aid of static illustrations (paper-based or displayed electronically, for example, on an $\mathrm{iPad}^{\mathrm{TM}}$ or other tablet) or with puppets, or as video clips in which the vignettes are played out $^{39,40}$. Typically, participants are requested to comment on the different stages of the story's progression $^{40}$. Vignettes should provide sufficient background and information to allow 
individuals to understand the scenario that is portrayed. However, the vignettes should also be vague enough to allow them to respond to the open-ended questions about the story or fill in missing detail.

In Johnson's study, where children's use of pain-related vocabulary was investigated, a story grammar format was used to develop vignettes for younger children (aged 6;0 to $9 ; 11)^{23,36}$. The story grammar format allowed for the compilation of a series of similarly structured short stories (vignettes), each of which related a set of events in a similar predictable order ${ }^{44,45}$. To determine the themes of the vignettes, the researchers collected input from children ${ }^{23,36}$ and asked them to draw pictures of their previous painful experiences. The children then discussed these with the first author, who subsequently identified the themes and stories to be used in the vignettes ${ }^{36}$. The same children selected a cartoon character from four possible options for the character who would feature in the vignettes, as well as a gender, language and ethnic neutral name for the character (Ziggy) ${ }^{36}$. The children were involved in providing the content of the vignettes and selected the character, enabling them to relate to the vignettes, and thus, this character was successful in eliciting appropriate pain-related vocabulary ${ }^{23}$. Where possible, vignettes should be developed with the input of the target audience themselves (in this case children).

The story grammar structure, as well as the specific vocabulary and syntax used in the vignettes should also be appropriate for participants' age and language levels, so as to ensure their comprehension and enable them to answer questions afterwards ${ }^{45}$. The repetitive format of a story grammar structure also increases the predictability of the text, an element that has been reported as increasing children's enjoyment of stories ${ }^{46}$. In the same way, a story grammar format, easy vocabulary, and short sentences could be used for young children as well as persons with learning disabilities to avoid information overload ${ }^{39}$. 
Hypothetical pain scenarios with vignettes to elicit pain words from children were also employed by Azize et al. ${ }^{47}$. They used some of the scenarios from the Pediatric Pain Inventory - a set of hypothetical scenarios with illustrations developed by Lollar ${ }^{48}$. Based on the success with which the use of hypothetical scenarios were used to elicit appropriate painrelated vocabulary in the studies of Johnson ${ }^{23}$ and Azize ${ }^{47}$, the same method may be appropriate for the selection of vocabulary for other sensitive topics, such as bullying, neglect, abuse, and death.

\section{PHASE 2: DIFFERENT INFORMANT GROUPS WITH DIFFERENT}

\section{PERSPECTIVES}

During the process of selecting vocabulary for children in need of AAC, SLPs would normally consult various proxy informants such as parents, teachers and therapists to suggest the best possible list of core and fringe words to be placed on an AAC communication system $^{11,49}$. These adults are typically selected based on their experience and expertise, and they would suggest the expected vocabulary children would use and need for a specific activity - such as eating or playing ${ }^{7,49,50}$. However, children could well use different words and phrases than those suggested by adults ${ }^{11}$, as a child's perspectives may differ from that of an adult ${ }^{49}$. It is therefore important to involve both child informants and adult informants when selecting vocabulary for children's AAC systems.

Accordingly, in the study by Johnson, the input from three groups of informants was obtained to compile a composite list of children's pain-related vocabulary. Informants included peers with typical development aged 6;0 to $9 ; 11$, as well as the parents and teachers of children in this age group ${ }^{36}$. Results revealed that only $13 \%$ (12) of the 87 pain-related words and phrases in the composite list appeared in the data of all three of the informant groups. Furthermore, statistically significant differences were found when the responses from 
the children were compared to those of the adults. This indicated that children provided different words and/or phrases than the two adult respondent groups (parents and teachers). What was not expected was that no statistically significant difference was found between the data of the two adult groups (parents and teachers). Researchers should therefore carefully consider who may serve as suitable participants (or informants) for a vocabulary selection process. Questions should be asked about the specific contribution that a particular informant could make in this process. One important consideration is to try to include the possible peers of the person in need of the vocabulary in the vocabulary selection process. In other words, during vocabulary selection for children who need or use AAC, "the child's perspective" as opposed to simply employing "a child perspective" $"$ is highlighted. Obtaining the child's perspective by talking directly to children about a specific topic related to them could thus reveal the rich and descriptive language children themselves may want to use to express their specific experiences - should it be pain, abuse or another sensitive topic ${ }^{5,51,52}$.

The fact that more than one respondent group was included in determining children's pain-related vocabulary added to the comprehensiveness of the vocabulary list identified by Johnson $^{36}$. Each group informed and added to the responses of the other groups ${ }^{36}$. On the other hand, the inclusion of two or more groups who shared similar features (such as parents and teachers) could result in similar data. The research indicated that one of these groups may have been superfluous and that effort and time might have been saved. Researchers should therefore think carefully when selecting informants to suit the specific topic. Different groups who are as diverse as possible should be purposefully included, for example, children and adults. Other factors that should also be carefully weighed are gender and language background, as they could potentially sway the information obtained (depending on the topic). 


\section{PHASE 3: STAKEHOLDER REVIEW}

Researchers have recognized the need to socially validate vocabulary selected for use by people who use AAC in different contexts ${ }^{1,8,10,19,29}$. To ensure that the selected vocabulary list is appropriate for use by persons who use AAC, SLPs should obtain the perspectives of persons with lived experiences (e.g., those who use AAC and their frequent communication partners). This procedure involves requesting stakeholders to evaluate the suitability and functionality of selected vocabulary ${ }^{1,8,19,53}$. Stakeholders' perspectives are important, because they are the persons who will use and need to live with the outcomes of the decisions made by the SLPs ${ }^{53}$. For this reason Balandin and Iacono ${ }^{8,13}$ argue that social validation of selected vocabulary is a significant process and that vocabulary should not be accepted before it has not been socially validated.

Both direct stakeholders (persons who use AAC) and indirect stakeholders (family members of the person who uses AAC) could be involved ${ }^{29}$ in the social validation process. Social validation by stakeholders who are competent users of AAC offers useful guidelines that could improve the quality of the proposed vocabulary list, since such stakeholders can infer the usefulness of the vocabulary lists directly from their personal experiences of needing to rely on AAC and also on preselected vocabulary ${ }^{29,54}$. In the study by Johnson ${ }^{23,36}$, social validation of the proposed list of pain-related words and phrases involved individual interviews with literate adults using AAC. When they were asked specific pain-related questions, these stakeholders were able to practically implement a communication board that displayed the pain-related words and phrases from the list ${ }^{23,36}$. Furthermore, the stakeholders provided valuable suggestions on the implementation of the pain-related vocabulary list. For example, they indicated that by displaying single words rather than phrases, children would be able to generate more messages, including novel messages, and not only pain-related messages. As a result, the composite vocabulary list was categorized according to core words 
(based on the children's core vocabulary lists as discussed earlier), as well as fringe words pain-related and other.

Another recommendation by the stakeholders was to use a body figure on the communication board to enable children to point at the specific body part where pain is experienced, rather than providing them with symbols indicating various body parts. By doing this, the limited vocabulary that could be displayed on a communication board could focus on describing the pain, exclamations, coping strategies, and so forth, rather than allocate space to describe the pain location. Body figures were also included on the Vidatak EZ Boards ${ }^{\mathrm{TM}}$ that were developed by Patak and colleagues ${ }^{55}$ and on the abuse boards that Bornman and colleagues developed ${ }^{56}$ for persons with significant communication difficulties to report abuse.

Schlosser ${ }^{29}$ proposed various options for conducting social validation assessments, such as interviews, direct observations, questionnaires, Likert-type scales, and experiments. In a study by Bornman and Bryen ${ }^{1}$ where the researchers socially validated vocabulary for disclosing abuse of literate adults who use text-based AAC systems were requested to indicate the importance of vocabulary items to be included on a communication board. They were asked to indicate the items on a 5-point Likert scale, ranging from 1=not important to include at all, to $5=$ very important to include ${ }^{1}$. Johnson and colleagues ${ }^{23}$ used individual interviews with literate adult stakeholders who use AAC during this social validation process. The involvement of persons in need of and/or using AAC to provide social validation may necessitate that methods have been adapted to ensure that their voices and opinions are indeed heard and not pre-empted or inferred ${ }^{57}$. Another social validation option that could be investigated is the use of a Talking Mats ${ }^{\mathrm{TM}}$ procedure $^{58,59}$. Talking Mats ${ }^{\mathrm{TM}}$ is a visual framework consisting of a textured mat or a piece of carpet of approximately $60 \mathrm{~cm} \mathrm{x} 30 \mathrm{~cm}$, on which graphic symbols can be displayed on a specific visual rating scale (e.g., Agree, 
Unsure, Disagree $)^{58-60}$. The Talking Mats ${ }^{\mathrm{TM}}$ procedure has been used in previous studies to obtain the perspectives of, for example, children and adults with communication and/or intellectual disabilities ${ }^{57,61-63}$.

For the social validation process of vocabulary on sensitive topics, Bornman and Bryen ${ }^{1}$ highlighted the importance of implementing empowerment methodology when participants with significant communication difficulties are involved. If the participants already have a relationship with the researchers, possible exploitation and power differentials could be reduced, thus maximizing reciprocity. However, researchers should also be cautious and avoid breeding familiarity during a stakeholder review process, as this may result in participants trying to behave in a socially desirable way by responding positively to most of the items, hence leading to the so-called Hawthorne effect ${ }^{64}$.

\section{PHASE 4: CUSTOMIZATION OF VOCABULARY}

As discussed earlier, a pre-established vocabulary list will rarely ever suffice to address the individual and unique communication needs of all persons ${ }^{24}$. Everyone has unique experiences due to his/her specific needs and circumstances. For example, the way in which people experience pain may differ from person to person, as pain experiences are subjective in nature. The reaction to tissue injury is not only based on biological processes responsible for these pain experiences - it is informed by the sum of sensory, emotional, and cognitive responses to pain $^{65}$. For the same reason, experiences related to sensitive issues such as abuse will remain unique and individual. Therefore, the vocabulary list that has been identified should be used as a basis to find and customize vocabulary that would suit the specific individual's needs - as such a communication board for a sensitive topic should never be duplicated for another person. The content should be revised and examined continuously to choose suitable vocabulary for a specific individual. 
One may think of this customization as the social validation of a generic list for an individual, with person-specific changes, omissions, and additions. Similar to Phases 2 and 3 described earlier, customization once again requires the input of various stakeholders ${ }^{16}$, most notably the individual for whom the vocabulary is intended. Once again, the extent to which this vocabulary truly represents what the person in need of AAC wants to communicate is dependent on the degree to which informants can 'put themselves into his/her shoes', their openness and willingness to do $\mathrm{so}^{32}$, their knowledge of language structure and how to design systems that maximize the potential for generative expression while also being appropriate to the capability profile of the person using them ${ }^{5,11}$, and their creativity and skill in obtaining the views of the person for whom the system is intended ${ }^{1}$.

\section{CONCLUSION}

Traditional methods for vocabulary selection may not always be sufficient when attempts are made to pre-select vocabulary that allows persons using AAC to discuss sensitive topics. The model developed by Johnson and colleagues ${ }^{23,36}$ was proposed as an alternative method. The four phases proposed include the use of hypothetical scenarios, the involvement of informants with different perspectives, social validation by stakeholders, as well as a process of customization of the generated vocabulary to suit the unique needs of each individual. While single-meaning graphic symbol-based AAC systems remain limited in the number of concepts they provide access to, "a few well-chosen words", p. 147 can go a long way to promote more autonomous expression on a variety of important topics by persons in need of AAC. All clinicians are therefore encouraged to consider these steps when compiling vocabulary lists, and even more so if the vocabulary is related to a sensitive topic. Although sensitive topics are not discussed frequently, their significance in enhancing the 
safety, well-being, and quality of life for persons in need of AAC should not be underestimated.

\section{REFERENCES}

1. Bornman J, Bryen DN. Social validation of vocabulary selection: Ensuring stakeholder relevance. Augmentative and Alternative Communication. 2013;29(2):174-181.

2. Light J, Parsons AR, Drager K. There's more to life than cookies": Developing interactions for social closeness with beginning communicators who use AAC. Exemplary practices for beginning communicators: Implications for AAC. 2002:187-218.

3. Light J. Interaction involving individuals using augmentative and alternative communication systems: State of the art and future directions. Augmentative and alternative communication. 1988;4(2):66-82.

4. Carlson F. A format for selecting vocabulary for the nonspeaking child. Language, Speech, and Hearing Services in Schools. 1981;12(4):240-245.

5. Snodgrass MR, Stoner JB, Angell ME. Teaching Conceptually Referenced Core Vocabulary for Initial Augmentative and Alternative Communication. Augmentative and Alternative Communication. 2013;29(4):322-333.

6. Reichle J, Drager K, Caron J, Parker-McGowan Q. Playing the Long Game: Considering the Future of Augmentative and Alternative Communication Research and Service. Paper presented at: Seminars in Speech and Language2016.

7. Morrow DR, Mirenda P, Beukelman DR, Yorkston KM. Vocabulary Selection for Augmentative Communication SystemsA Comparison of Three Techniques. Am. J. Speech Lang. Pathol. 1993;2(2):19-30.

8. Balandin S, Iacono T. A few well-chosen words. Augmentative and Alternative communication. 1998;14(3):147-161. 
9. Bryen DN. Vocabulary to support socially-valued adult roles. Augmentative and Alternative Communication. 2008;24(4):294-301.

10. Yorkston K, Dowden P, Honsinger M, Marriner N, Smith K. A comparison of standard and user vocabulary lists. Augmentative and Alternative Communication. 1988;4(4):189210.

11. Beukelman DR, Mirenda P. Augmentative and Alternative Communication. Supporting Children and Adults with Complex Communication Needs. 4 ed2013.

12. Boenisch J, Soto G. The Oral Core Vocabulary of Typically Developing EnglishSpeaking School-Aged Children: Implications for AAC Practice. Augmentative and Alternative Communication. 2015;31(1):77-84.

13. Balandin S, Iacono T. Topics of meal-break conversations. Augmentative and Alternative Communication. 1998;14(3):131-146.

14. Banajee M, Dicarlo C, Buras Stricklin S. Core vocabulary determination for toddlers. Augmentative and Alternative Communication. 2003;19(2):67-73.

15. Fallon KA, Light J, Page TK. Enhancing Vocabulary Selection for Preschoolers Who Require Augmentative and Alternative Communication (AAC). American Journal of Speech-Language Pathology and Immunopathology Research. 2001;10(81-94).

16. Fried-Oken M, More L. An initial vocabulary for nonspeaking preschool children based on developmental and environmental language sources. Augmentative and Alternative Communication. 1992;8(1):41-56.

17. Marvin C, Beukelman DR, Bilyeu D. Vocabulary-use patterns in preschool children: Effects of context and time sampling. Augmentative and Alternative Communication. 1994;10(4):224-236.

18. Trembath D, Balandin S, Togher L. Vocabulary selection for Australian children who use augmentative and alternative communication. Journal of Intellectual and Developmental Disability. 2007;32(4):291-301. 
19. Beukelman DR, McGinnis J, Morrow D. Vocabulary selection in augmentative and alternative communication. Augmentative and Alternative Communication. 1991;7(3):171-185.

20. Stuart S, Beukelman DR, King J. Vocabulary use during extended conversations by two cohorts of older adults. Augmentative and alternative communication. 1997;13(1):40-47.

21. Goossens C, Crain S, Elder PS. Communication displays for engineered preschool environments. Solana Beach, CA: Mayer-Johnson Company; 1994.

22. Goossens' C. Aided communication intervention before assessment: A case study of a child with cerebral palsy. Augmentative and Alternative Communication. 1989;5(1):1426.

23. Johnson E, Bornman J, Tönsing KM. An exploration of pain-related vocabulary: implications for AAC use with children. Augmentative and Alternative Communication. 2016:1-12.

24. Balandin S, Iacono T. Crews, wusses, and whoppas: Core and fringe vocabularies of Australian meal-break conversations in the workplace. Augmentative and Alternative Communication. 1999;15(2):95-109.

25. Hill K. Augmentative and alternative communication and language: Evidence-based practice and language activity monitoring. Topics in Language Disorders. 2004;24(1):1830.

26. Beukelman DR, Yorkston KM, Poblete M, Naranjo C. Frequency of word occurance in communication samples produced by adult communication aid users. J. Speech Hear. Disord. 1984;49:360-367.

27. Karlan GR, Lloyd LL. Considerations in the planning of communication intervention: Selecting a lexicon. Journal of the Association for the Severely Handicapped. $1983 ; 8(2): 13-25$. 
28. Tönsing KM, Alant E. Topics of social conversation in the work place: A South African perspective. Augmentative and Alternative Communication. 2004;20(2):89-102.

29. Schlosser RW. Social validation of interventions in augmentative and alternative communication. Augmentative and Alternative Communication. 1999;15(4):234-247.

30. Lee YM, Kim YT, Park EH. A preliminary study for the core and fringe AAC vocabulary used by elementary school students. Communication Sciences \& Disorders. 2005;10(1):134-152.

31. Da Fonte MA, Pufpaff LA, Taber-Doughty T. Vocabulary use during storybook reading: Implications for children with augmentative and alternative communication needs. Psychology in the Schools. 2010;47(5):514-524.

32. Brewster S. Saying the ' $F$ word... in the nicest possible way': augmentative communication and discourses of disability. Disability \& Society. 2013;28(1):125-128.

33. Wennström B, Bergh I. Bodily and Verbal Expressions of Postoperative Symptoms in 3to 6-Year-Old Boys. J. Pediatr. Nurs. 2008;23(1):65-76.

34. Stanford EA, Chambers CT, Craig KD, McGrath PJ, Cassidy KL. "Ow!": Spontaneous verbal pain expression among young children during immunization. Clin. J. Pain. // 2005;21(6):499-502.

35. Herr K, Coyne PJ, McCaffery M, Manworren R, Merkel SI. Pain assessment in the patient unable to self-report: position statement with clinical practice recommendations. Pain Manag. Nurs. 2011;12(4):230-250.

36. Johnson E. An exploration of the common pain-related vocabulary typically-developing children use: Implications for children who use AAC. Pretoria: Centre for Augmentative and Alternative Communication, University of Pretoria; 2015.

37. Braun V, Clarke V. Successful Qualitative Research: A Practical Guide for Beginners London: SAGE; 2013. 
38. Belter RW, McIntosh JA, Finch Jr AJ, Saylor CF. Preschoolers' ability to differentiate levels of pain: relative efficacy of three self-report measures. J. Clin. Child Psychol. 1988;17(4):329-335.

39. Hughes R, Huby M. The application of vignettes in social and nursing research. $J$. $A d v$. Nurs. 2002;37(4):382-386.

40. Jenkins N, Bloor M, Fischer J, Berney L, Neale J. Putting it in context: the use of vignettes in qualitative interviewing. Qualitative Research. 2010;10(2):175-198.

41. Schoenberg NE, Ravdal H. Using vignettes in awareness and attitudinal research. International Journal of Social Research Methodology. 2000;3(1):63-74.

42. Rahman N. Caregivers' sensitivity to conflict: The use of the vignette methodology. Journal of Elder Abuse \& Neglect. 1996;8(1):35-47.

43. Chan KY, Yang Y, Zhang K, Reidpath DD. Disentangling the stigma of HIV/AIDS from the stigmas of drugs use, commercial sex and commercial blood donation-a factorial survey of medical students in China. BMC Public Health. 2007;7(1):280.

44. Hayward D, Schneider P. Effectiveness of teaching story grammar knowledge to preschool children with language impairment. An exploratory study. Child Language Teaching and Therapy. 2000;16(3):255-284.

45. Whaley JF. Story Grammars and Reading Instruction. The Reading Teacher. 1981;34(7):762-771.

46. Montague M, Maddux CD, Dereshiwsky MI. Story grammar and comprehension and production of narrative prose by students with learning disabilities. J. Learn. Disabil. 1990;23(3):190-197.

47. Azize PM, Endacott R, Cattani A, Humphreys A. Cultural responses to pain in UK children of primary school age: A mixed- methods study. Nurs. Health Sci. 2013.

48. Lollar DJ, Smits SJ, Patterson DL. Assessment of pediatric pain: an empirical perspective. J. Pediatr. Psychol. 1982;7(3):267-277. 
49. Roulstone $\mathrm{S}$. Exploring the relationship between client perspectives, clinical expertise and research evidence. Int. J. Speech Lang. Pathol. 2015(0):1-11.

50. Beyer JE, Wells N. The assessment of pain in children. Pediatr. Clin. North Am. 1989;36(4):837-854 .

51. Nilsson S, Björkman B, Almqvist A, et al. Children's voices - differentiating a child perspective from a child's perspective. Developmental Neurorehabilitation. 2013(0):1-7.

52. Ely J. The experience of pain for school-age children: Blood, band-aids, and feelings. Children's Health Care. 1992;21(4):168-175.

53. Schlosser RW, Raghavendra P. Evidence-based practice in augmentative and alternative communication. Augmentative and Alternative Communication. 2004;20(1):1-21.

54. Kildea S, Wright J, Davies J. Making sense of ADHD in practice: A stakeholder review. Clinical child psychology and psychiatry. 2011;16(4):599-619.

55. Patak L, Gawlinski A, Fung NI, Doering L, Berg J, Henneman EA. Communication boards in critical care: patients' views. Appl. Nurs. Res. 11// 2006;19(4):182-190.

56. Bornman J, Bryen DN, Kershaw P, Ledwaba G. Reducing the Risk of Being a Victim of Crime in South Africa: You can tell and be Heard! Augmentative and Alternative Communication. 2011;27(2):117-130.

57. Brewster S. Putting words into their mouths? Interviewing people with learning disabilities and little/no speech. British Journal of Learning Disabilities. 2004;32(4):166169.

58. Murphy J, Tester S, Hubbard G, Downs M, MacDonald C. Enabling frail older people with a communication difficulty to express their views: the use of Talking Mats ${ }^{\mathrm{TM}}$ as an interview tool. Health Soc. Care Community. 2005;13(2):95-107.

59. Murphy J, Cameron L. The effectiveness of Talking Mats ${ }^{\mathrm{TM}}$ with people with intellectual disability. British Journal of Learning Disabilities. 2008;26(4):232-241. 
60. Murphy J, Boa S. Using the WHO-ICF with Talking Mats to enable adults with long-term communication difficulties to participate in goal setting. Augmentative and Alternative Communication. 2012;28(1):52-60.

61. Donohue DK, Bornman J, Granlund M. Examining the rights of children with intellectual disability in South Africa: Children's perspectives. Journal of Intellectual and Developmental Disability. 2014;39(1):55-64.

62. Erasmus A, Bornman J, Dada S. Afrikaans-speaking parents' perceptions of the rights of their children with mild to moderate intellectual disabilities: A descriptive investigation. Journal of Child Health Care. 2016;20(2):234-242.

63. Pettit LK, Tönsing KM, Dada S. The perspectives of adults with aphasia and their team members regarding the importance of nine life areas for rehabilitation: a pilot investigation. Topics in stroke rehabilitation. 2016:1-8.

64. Kottner J, Audige L, Brorson S, et al. Guidelines for reporting reliability and agreement studies (GRRAS) were proposed. Int. J. Nurs. Stud. 2011;48(6):661-671.

65. Schiavenato M, Craig KD. Pain assessment as a social transaction: beyond the "gold standard". The Clinical journal of pain. 2010;26(8):667-676. 